\title{
POLA PENGGUNAAN INSULIN PADA PASIEN DIABETES MELITUS TIPE I DI INSTALASI RAWAT JALAN RSUP PROF. DR. R. D. KANDOU MANADO
}

\author{
Mutia Djahido $^{1)}$, Weny I. Wiyono ${ }^{1)}$, Deby A. Mpila ${ }^{1)}$ \\ ${ }^{1)}$ Program Studi Farmasi FMIPA UNSRAT Manado, 95115
}

\begin{abstract}
Diabetes mellitus type I is a condition which characterized by a high levels of sugar or glucose in the blood. Type I diabetes mellitus occurs when the body produces less or no insulin. As a result, people with type I diabetes require additional insulin from outside. Normally the level of sugar in the blood is controlled by the hormone insulin produced by the pancreas. The study aimed to determine the pattern of insulin use in patients with Type I Diabetes Mellitus in RSUP. Prof. Dr. R. D. Kandou Manado. Sampling used a descriptive method with a retrospective research design of medical record data that met the inclusion criteria. The sample of this study were 24 patients. The pattern of insulin use is based on the correct evaluation of 24 patients (100\%), the right dose of 19 patients (76.16\%), the right drug 24 patients (100\%), the right indication of 24 patients (100\%).
\end{abstract}

Keywords: Diabetes mellitus type I, insulin, outpatient.

\begin{abstract}
ABSTRAK
Diabetes Melitus tipe I adalah kondisi yang ditandai dengan tingginya kadar gula atau glukosa dalam darah. Diabetes melitus tipe I terjadi ketika tubuh kurang atau sama sekali tidak memproduksi insulin. Akibatnya, penderita Diabetes Melitus tipe I memerlukan tambahan insulin dari luar. Normalnya kadar gula dalam darah dikontrol oleh hormon insulin yang dihasilkan oleh pankreas. Penelitian ditujukan untuk mengetahui pola penggunaan insulin pada pasien Diabetes Melitus Tipe I di RSUP. Prof. Dr. R. D. Kandou Manado. Pengambilan sampel menggunakan metode deskriptif dengan desain penelitian retrospektif dari data rekam medik yang memenuhi kritera inklusi. Sampel penelitian ini sebanyak 24 pasien. Pola penggunaan insulin berdasarkan evaluasi tepat pasien sebanyak 24 pasien (100\%), tepat dosis sebanyak 19 pasien $(79,16 \%)$, tepat obat sebanyak 24 pasien (100\%), tepat indikasi sebanyak 24 pasien (100\%).
\end{abstract}

Kata kunci : Diabetes Melitus tipe I, insulin, rawat jalan 


\section{PENDAHULUAN}

Diabetes Melitus (DM) merupakan salah satu masalah kesehatan yang besar di Indonesia. Berdasarkan data dari World Health Organization (WHO), sekitar 347 juta orang di seluruh dunia menderita diabetes, dan diperkirakan bahwa kematian akibat diabetes akan meningkat dua pertiga kali antara tahun 2008 dan 2030. Beban diabetes meningkat secara global khususnya di negara-negara berkembang. Menurut International Diabetes Federation (IDF, 2011). Pada tahun 2011, Indonesia menempati urutan ke-10 jumlah penderita Diabetes Melitus (DM) terbanyak di dunia dengan jumlah 7,3 juta orang dan jika hal ini berlanjut diperkirakan pada tahun 2030 penderita DM dapat mencapai 11.8 juta orang. Provinsi Sulawesi Utara merupakan salah satu provinsi dengan prevalensi DM yang cukup tinggi. Menurut data Riskesdas tahun 2007, prevalensi penyakit DM di Provinsi Sulawesi Utara berada pada peringkat ke enam yaitu sebesar $8,1 \%$ (Dinkes Provinsi Sulawesi Utara, 2016).

Diabetes melitus tipe I merupakan penyakit kronis yang tidak dapat di sembuhkan, namun penyakit ini dapat dikelola dengan memperhatikan gaya hidup dan pola makan yang disarankan oleh ahli kesehatan agar kadar gula darah terkontrol dengan baik. Penyakit diabetes melitus tipe I tidak akan semakin parah dan timbul komplikasi namun, apabila penyakit Diabetes melitus tersebut telah timbul komplikasi, maka perlakuan yang paling efektif untuk penderita diabetes berat adalah dengan pengelolaan diri yang kompleks dan akan memakan waktu lama agar kadar gula darah dapat terkontrol dengan ketat. Diabetes melitus tipe I jika tidak dikelola dengan baik akan menyebabkan penyakit jantung koroner, penyakit pembuluh darah tungkai, ginjal dan syaraf. Diabetes melitus menimbulkan komplikasi, yang mempengaruhi mata, ginjal, dan sistem saraf perifer. Penyebab terbanyak dari kehilangan sel beta pada diabetes melitus tipe 1 merupakan kesalahan reaksi autoimunitas yang menghancurkan sel beta pankreas. Reaksi autoimunitas tersebut dapat dipicu oleh adanya infeksi pada tubuh. Saat ini diabetes melitus tipe 1 hanya dapat diobati dengan menggunakan insulin, dengan pengawasan yang teliti terhadap tingkat glukosa darah melalui alat monitor pengujian darah (Cantril et al, 2003).

Insulin adalah hormon alami yang dikeluarkan oleh pankreas. Insulin dibutuhkan oleh sel tubuh untuk mengubah dan menggunakan glukosa darah (gula darah), dari glukosa, sel membuat energi yang dibutuhkan untuk menjalankan fungsinya. Diabetes Melitus tipe I yang tergantung pada insulin ini disebabkan akibat kekurangan insulin dalam darah yang terjadi karena kerusakan dari sel beta pankreas (ADA, 2011).

Menurut penelitian sebelumnya yang dilakukan oleh Wisman et al, (2007) pemberian insulin pada pasien dengan diabetes melitus tipe I merupakan keharusan karena belum ada terapi lain yang dapat dipakai dalam mengobati diabetes melitus tipe I

Dengan demikian peneliti melakukan penelitian mengenai pola penggunaan insulin pada pasien diabetes melitus tipe I di Manado yang menjalani 
rawat jalan di RSUP. Prof. Dr. R. D. Kandou Manado karena pemberian insulin pada DM tipe I merupakan keharusan karena belum ada terapi lain yang dapat dipakai dalam mengobati DM tipe I.

\section{METODOLOGI PENELITIAN}

\section{Waktu dan Tempat Penelitian}

Penelitian ini dilakukan di ruang rekam medik RSUP Prof. Dr. R. D. Kandou Manado dan waktu penelitian dimulai pada bulan Juli - Oktober 2019.

\section{Jenis Penelitian}

Penelitian ini dilakukan dengan metode deskriptif, yaitu suatu penelitian yang dilakukan dengan cara pendekatan observasi, pengumpulan data sekaligus pada satu waktu dan menggunakan data yang sudah ada. Pengambilan data dilakukan secara retrospektif. Bahan dan sumber data dari penelitian ini diperoleh dari rekam medis pasien diabetes melitus tipe I yang dirawat jalan RSUP. Prof. Dr. R. D. Kandou Manado periode JanuariDesember 2018.

\section{Alat dan Bahan}

Alat dan bahan yang di gunakan dalam penelitian ini, yaitu American Assosiation of Clinical Endocrinologists (AACE 2013), Medical Guidelines for Clinical Practice for the Management of Diabetes Mellitus 2012, American Diabetes Association (ADA 2014), Diagnosis and Classification of Diabetes Mellitus. Petunjuk praktis Terapi Insulin Pada Pasien Diabetes Melitus Perkeni (2011). Data rekam medik berisi deskripsi pasien (umur, jenis kelamin, berat badan), keluhan utama, diagnosis penyakit, data penggunaan obat pasien selama rawat jalan, data hasil pemeriksaan fisik dan laboratorium.

\section{Subjek Penelitian}

Subjek dalam penelitian ini adalah seluruh pasien rawat jalan yang didiagnosa diabetes melitus tipe I yang telah menjalani pengobatan. Sampel terdiri dari semua pasien yang menderita diabetes melitus tipe 1 yang menjalani perawatan rawat jalan RSUP. Prof. Dr. R. D. Kandou Manado periode Januari - Desember 2018.

\section{Teknik Pengambilan Sampel}

Teknik pengambilan sampel yaitu non-probability dimana teknik pengambilan sampel ditentukan sendiri oleh peneliti yaitu berdasarkan kriteria spesifik yang ditetapkan peneliti, sebagai berikut:

1. Kriteria inklusi

a. Pasien dengan diagnosa Diabetes Melitus Tipe I dengan atau tanpa penyakit penyerta di rawat jalan di RSUP. Prof. Dr. R. D. Kandou Manado.

b. Usia $<35$ Tahun

2. Kriteria eksklusi

Data rekam medik yang tidak lengkap misalnya jenis kelamin, usia, obat dan dosis yang tidak ada atau kurang jelas.

\section{Pengumpulan Data}

Pengumpulan data dilakukan dengan melihat data sekunder yang berasal dari rekam medis pasien. Data yang dikumpulkan berasal dari data rekam medik, diantaranya: jenis kelamin, umur, pemberian insulin dan dosis insulin. Setelah data dikumpulkan kemudian akan dipindahkan ke lembar pengumpulan data.

\section{Analisis Data}


Data yang telah dikumpulkan di Lembar Pengumpulan Data (LPD) dilakukan analisis deskriptif, yaitu dengan mendeskriptif pasien (nama, umur, jenis kelamin, berat badan, riwayat penyakit terdahulu, dan lain-lain) dan menganalisa pola pengobatan yang terdiri dari tepat dosis, tepat indikasi, tepat obat, tepat pasien. Selanjutnya data tersebut disajikan dalam bentuk tabel dan presentase.

\section{HASIL}

Pada penelitian ini setelah dilakukan pemilihan sampel penelitian berdasarkan kriteria inklusi dan eksklusi didapatkan jumlah sampel sebanyak 24 pasien. Karakteristik subjek penelitian berdasarkan jenis kelamin, usia dan diagnosa. Pada penelitian ini data jenis kelamin, usia, dan diagnosa pasien diabetes melitus tipe I yang menjalani rawat jalan di RSUP Prof. Dr. R. D. Kandou Manado dapat dilihat pada Tabel 1 dibawah ini. Tabel 1. Karakteristik Pasien Diabetes Melitus Tipe I Berdasarkan Jenis Kelamin, Usia, dan Diagnosa

\begin{tabular}{ccc}
\hline Karakteristik & $\begin{array}{c}\text { Jumlah } \\
\text { Penderita } \\
(\mathbf{n})\end{array}$ & $\begin{array}{c}\text { Presenta } \\
\text { se }(\%)\end{array}$ \\
\hline Jenis Kelamin & & \\
\hline Laki-laki & 10 & 41,66 \\
Perempuan & 14 & 58,33 \\
\hline Usia & & \\
\hline $5-11$ & 12 & 50 \\
$12-16$ & 5 & 20,83 \\
$17-25$ & 1 & 4,17 \\
$26-35$ & 6 & 25 \\
& & \\
\hline Diagnosa & & \\
\hline
\end{tabular}

\begin{tabular}{lll}
\hline $\begin{array}{c}\text { Ketoasidosis } \\
\text { Diabetikum }\end{array}$ & 24 & 100 \\
\hline
\end{tabular}

Pada Tabel 1 dapat dilihat bahwa pasien yang terdiagnosa diabetes melitus tipe I sebanyak 24 pasien, Kelompok usia terbanyak pada kelompok usia 5-11 tahun sebanyak 12 pasien $(50 \%)$.

\section{Pola Penggunaan Insulin}

\section{Pola penggunaan insulin berdasarkan} lama kerja

Tabel 2. Penggunaan Insulin Berdasarkan Lama Kerja

\begin{tabular}{ccc}
\hline Jenis Insulin & $\begin{array}{c}\text { Jumlah } \\
(\mathbf{n = 2 4 )}\end{array}$ & $\begin{array}{c}\text { Presentase } \\
(\%)\end{array}$ \\
\hline $\begin{array}{c}\text { Long acting } \\
\text { Insulin } \\
\text { Rapid acting } \\
\text { Insulin }\end{array}$ & 9 & 34,61 \\
\hline Total & 17 & 63,39 \\
\hline
\end{tabular}

Berdasarkan lama kerja insulin, penggunaan insulin terbanyak yaitu Rapid acting insulin sebanyak 17 sebesar $65,39 \%$.

\section{Pola Penggunaan Insulin Berdasar kan Dosis Harian}

Tabel 3. Pengggunaan Insulin Berdasarkan Dosis Harian

\begin{tabular}{|c|c|c|}
\hline $\begin{array}{l}\text { Jumlah dosis harian } \\
\text { (IU) }\end{array}$ & $\begin{array}{c}\text { Jumlah } \\
(\mathrm{n}=24)\end{array}$ & $\begin{array}{c}\text { Presen } \\
\text { tase } \\
(\%)\end{array}$ \\
\hline Long acting insulin & 9 & 34,61 \\
\hline$<20 \mathrm{IU}$ & 8 & 30,76 \\
\hline 21-40 IU & 1 & 3,84 \\
\hline$>40 \mathrm{IU}$ & - & - \\
\hline Rapid acting insulin & 17 & 65,39 \\
\hline$<20 \mathrm{IU}$ & 17 & 65,39 \\
\hline $21-40 \mathrm{IU}$ & - & - \\
\hline$>40 \mathrm{IU}$ & - & - \\
\hline \multicolumn{3}{|l|}{ Kombinasi } \\
\hline Novorapid+Levemir & 2 & 8,33 \\
\hline
\end{tabular}


Dosis harian terbanyak digunakan yaitu long acting insulin dan rapid acting insulin < 20 IU dari seluruh jenis insulin yang di gunakan dan jenis kombinasi 2 jenis insulin yaitu Novorapid dengan levemir sebanyak 2 pasien sebesar $(8,33 \%)$.

Ketepatan Penggunaan Insulin

Tabel 4. Ketepatan Penggunaan Insulin

\begin{tabular}{lcccc}
\hline \multirow{2}{*}{$\begin{array}{c}\text { Kriteria } \\
\text { Ketepat } \\
\text { an }\end{array}$} & \multicolumn{3}{c}{$\begin{array}{c}\text { Evaluasi Penggunaan } \\
\text { Insulin }\end{array}$} \\
\cline { 2 - 5 } & \multicolumn{2}{c}{ Tepat } & \multicolumn{2}{c}{$\begin{array}{c}\text { Tidak } \\
\text { Tepat }\end{array}$} \\
\cline { 2 - 5 } & $\mathbf{n}$ & $\boldsymbol{\%}$ & $\mathbf{n}$ & $\boldsymbol{\%}$ \\
\hline Pasien & 24 & 100 & 0 & 0 \\
Dosis & 19 & 79,16 & 5 & 20,83 \\
Obat & 24 & 100 & 0 & 0 \\
Indikasi & 24 & 100 & 0 & 0 \\
\hline
\end{tabular}

\section{PEMBAHASAN}

Berdasarkan tabel 1, pasien Diabetes Melitus tipe I yang menggunakan insulin pada penelitian ini menunjukan bahwa perempuan dengan 14 pasien $(58,33 \%)$ lebih banyak di bandingkan lakilaki dengan 10 pasien $(41,66 \%)$. Hasil penelitian ini serupa yang dilakukan oleh Wisman et al (2007) terkait menunjukan jenis kelamin perempuan lebih banyak dibandingkan laki-laki. Namun menurut Soegondo et al (2005) jenis kelamin bukan termasuk faktor pemicu timbulnya penyakit diabetes melitus, karena yang menjadi faktor pemicunya adalah faktor keturunan, obesitas, dan pola makan yang salah.

Pembagian usia dalam penelitian ini berdasarkan American Diabetes Association (ADA, 2015), kelompok usia terbesar yang menderita Diabetes Melitus Tipe I terdapat pada kelompok usia 5-11 tahun $(50 \%)$. Penelitian sebelumnya yang dilakukan di Rumah Sakit Umum Dr.
Saiful Anwar Malang dalam kurun waktu antara tahun 2005-2009 menunjukan usia terbesar pada rentang usia 5-11 tahun yang dilakukan oleh Haryudi (2011). Rentang usia tersebut merupakan masa yang sangat rentan terkena infeksi. Kondisi infeksi akan meningkatkan autoantibodi yang berkembang menjadi diabetes melitus tipe I. Selain itu diperkirakan saat infeksi akan terjadi peningkatan sekresi kortisol dan glukagon sehingga terjadi peningkatan kadar gula darah yang bermakna. Sistem imun pada anak justru menghancurkan sel beta pankreas sehat yang menghasilkan insulin akibatnya pankreas anak diabetes tidak memproduksi insulin yang cukup dan sel-sel pankreas tidak bisa menghasilkan insulin sama sekali (ADA, 2015).

\section{Pola Penggunaan Insulin}

\section{Pola penggunaan insulin berdsarkan lama kerja}

Pada penelitian ini jenis insulin Rapid acting insulin ditemukan paling banyak digunakan pada 17 pasien sebesar $(65,39 \%)$. Penelitian sebelumnya yang dilakukan oleh Yulianti et al (2012) menunjukan bahwa terapi insulin digunakan adalah jenis Rapid acting insulin (35,29\%). Rapid acting insulin mempunyai daya absorbsi pada tempat suntikan lebih cepat (90\% dalam 100 menit) dibandingkan dengan Short acting insulin (90\% dalam 150 menit), puncak konsentrasi lebih tinggi dan lebih dini serta lama kerja lebih singkat (PERKENI, 2015).

\section{Pola penggunaan insulin berdasarkan dosis harian}

Pola penggunaan insulin berdasarkan jumlah dosis harian yang diperoleh dalam penelitian ini paling 
banyak pada dosis < 20 IU dari seluruh tipe insulin yang digunakan pada penelitian ini. Setelah dilakukan pemberian terapi insulin perlu dilakukan kontrol kadar GDS, apabila GDS masih tinggi maka dosis insulin dapat di tingkatkan 2-4 IU setiap kali pemberian, jumlah dosis harian untuk insulin sebesar 40 IU perhari. Secara umum kebutuhan insulin dapat diperkirakan yaitu insulin basal $50 \%$ dari kebutuhan insulin per hari atau 0,02 IU/kgBB (WHO 2016).

Jenis kombinasi insulin yang ditemukan dalam penelitian ini, yaitu long acting insulin dengan rapid acting insulin digunakan pada 2 pasien sebesar $(8,33 \%)$. Penelitian sebelumnya dilakukan oleh Baso et al (2014), kombinasi jenis insulin yang digunakan yaitu long acting insulin dan rapid acting insulin digunakan pada 17 pasien sebesar $(79,67 \%)$. Kombinasi 2 jenis insulin ini dapat memberikan penurunan kadar glukosa darah lebih baik karena dapat memenuhi kebutuhan insulin basal dan insulin prandial (PERKENI,2015).

\section{Ketepatan Penggunaan Insulin}

\section{Tepat Pasien}

Menurut Depkes RI (2005), tepat pasien merupakan kesesuaian pemberian insulin dengan keadaan atau kondisi masing-masing pasien. Dalam hal ini pemberian harus sesuai dengan kondisi pasien DM Tipe I . Pada penelitian ini evaluasi penggunaan insulin terkait kondisi pasien dilakukan dengan melihat pengobatan yang diterima pasien selama menjalani rawat jalan selain itu juga dilihat data hasil pemeriksaan fisik dan pemeriksaan laboratorium yang berpengaruh dalam menilai ketepatan obat terkait kondisi pasien. Hasil penelitian menunjukan bahwa kesesuaian pasien dengan pemberian insulin pada pasien Diabetes Melitus Tipe I dari data rekam medik di RSUP. Prof. Dr. R. D. Kandou Manado periode Januari-Desember 2018 berdasarkan standar PERKENI (2011) memenuhi kriteria tepat pasien sebesar $100 \%$.

\section{Tepat Dosis}

Dosis, cara, dan lama pemberian obat sangat berpengaruh terhadap efek terapi obat. Pemberian dosis yang berlebihan akan sangat beresiko timbulnya efek samping. Sebaliknya dosis yang terlalu kecil tidak akan menjamin tercapainya kadar terapi yang di harapkan (PERKENI, 2011).

Berdasarkan hasil penelitian diperoleh bahwa ketepatan dosis dalam penelitian ini 19 pasien $(79,16 \%)$, dimana terdapat 5 pasien $(20,83 \%)$ tidak tepat dosis. Ketidaktepatan pemberian dosis yang diberikan pada pasien dengan GDS 302 mg/dL 1IU/hari, pasien dengan GDS 325 $\mathrm{mg} / \mathrm{dL}$ dosis yang diberikan 2IU/hari, pasien dengan GDS $310 \mathrm{mg} / \mathrm{dL}$ dosis yang diberikan dosis yang diberikan 12IU/hari, pasien dengan GDS $327 \mathrm{mg} / \mathrm{dL}$ dosis diberikan 3IU/hari, pasien dengan GDS $340 \mathrm{mg} / \mathrm{dL}$ dosis yang diberikan 6IU/hari. Dimana pemberian dosis yang diberikan yaitu kurang dari 20 IU/hari seharusnya bila $($ GDS $)>300$ pemberian dosis insulin harus 20IU/hari menurut standar PERKENI (2011).

\section{Tepat Obat}

Tepat obat merupakan kesesuaian pemilihan suatu obat diantara beberapa jenis obat yang memiliki indikasi terhadap penyakit Diabetes Melitus Tipe I. Ketepatan penggunaan obat kategori tepat 
obat adalah ketepatan pemilihan obat yang mempertimbangkan ketepatan kelas terapi dan jenis obat, serta manfaat dan keamanan berdasarkan standar (PERKENI, 2011). Menurut (ADA, 2004), terapi insulin untuk keteosidosis diabetelikum menunjukan hasil klinis yang lebih baik. Hal tersebut diperlihatkan oleh perbaikan fungsi sel beta pankreas maka penderita mendapatkan insulin eksogen untuk membantu agar metabolisme karbohidrat di dalam tubuh dapat berjalan normal.

Berdasarkan hasil evaluasi ketepatan penggunaan obat dalam penelitian ini yang dilakukan di ruang rekam medik RSUP. PROF. Dr. R. D. Kandou Manado didapatkan dengan diagnosa keteosidosis diabetelikum yang berjumlah 24 pasien sebesar $(100 \%)$ yaitu dengan terapi insulin dan tidak menggunakan terapi obat.

\section{Tepat Indikasi}

Tepat indikasi merupakan kesesuaian penggunaan obat dengan kebutuhan klinis pasien yang dilihat dari diagnosis, gejala ataupun keluhan pasien. Long acting insulin umumnya digunakan untuk menjaga agar kadar gula darah tetap terkontrol dalam jangka waktu yang panjang. Rapid acting insulin digunakan untuk memberikan efek penurunan kadar gula darah yang cepat pada pasien setelah disuntikan ke dalam tubuh sesuai dengan dosis (PERKENI,2007).

Hasil penelitian terdapat 24 pasien sebesar (100\%) dengan diagnosa keteosidosis diabetelikum yang menggunakan golongan long acting insulin yaitu levemir dengan durasi kerja panjang dan golongan rapid acting insulin yaitu novorapid dan lispro dengan onset kerja yang cepat.

\section{KESIMPULAN}

Pada hasil penelitian diperoleh 24 pasien yang didiagnosa diabetes melitus tipe 1 sebagai subyek penelitian yang menjalani rawat jalan di RSUP. Prof. Dr. R. D. Kandou Manado. Insulin yang paling banyak digunakan, yaitu insulin rapid acting, 17 pasien (65,39\%); dan jenis kombinasi yang digunakan, yaitu rapid acting insulin dan long acting insulin seperti sebanyak 2 pasien $(8,33 \%)$. Pada pola penggunaan insulin ditemukan sebanyak, tepat obat 24 pasien $(100 \%)$, tepat pasien 24 pasien $(100 \%)$, tepat indikasi 24 pasien $(100 \%)$, tepat dosis 19 pasien $(76,16 \%)$

\section{SARAN}

Untuk peneliti selanjutnya perlu dilakukan penelitian dengan metode prospektif dan mencakup jumlah sampel yang lebih besar.

\section{DAFTAR PUSTAKA}

American Diabetes Association, 2011. Diagnosis and Classification of Diabetes Mellitus. Diabetes Care.

American Diabetes Association, 2015. Diabetes Care, USA.

American Diabetes Association, 2004. Standards of medical care in diabetes.Diabetes Care 27(1) : 1535 .

Baso Amri AY, Umar H, Manggau MA, 2014. Pengaruh terapi terhadap pasien diabetes melitus [skripsi]. FK UNHAS 
Cantrill. J.A and Wood .J. Diabetes Mellitus, in Walker $\mathrm{R}$ and Edwards $\mathrm{C}$ (2003). Clinical Pharmacy and Therapeutics third ed Churchill Livingstone. 30(1) : $657-677$.

Departemen Kesehatan Republik Indonesia, 2005. Pharmaceutical Care Untuk Penyakit Diabetes Mellitus, Departemen Kesehatan RI, Jakarta.

Dinas Kesehatan Provinsi Sulawesi Utara, (2016). Profil Kesehatan Provinsi Sulawesi Utara 2016, Manado.

Haryudi Aji, 2011. Gambaran Klinis Diabetes Melitus Tipe I pada Anak, Malang. 26 (4) : 195-198

International Diabetes Federation, 2011. Diabetes Atlas Fifth Edition.

Perkumpulan Endokrinilogi Indonesia (Perkeni), 2011. Konsensus Pengolahan dan Pencegahan Diabetes Melitus di Indonesia. Perkeni, Jakarta.

Perkeni, 2015. Petunjuk Praktis Terapi Insulin Pada Pasien Diabetes Melitus. Perkeni, Jakarta.

Perkeni, 2007. Petunjuk Praktis Terapi Insulin pada Pasien Diabetes Melitus. Perkeni, Jakarta

World Health Organization, 2016. Diabetes Melitus, World Health Organization

Wisman, Hakimi, Charles.D.Siregar 2007. Pemberian Insulin pada Diabetes
Melitus Tipe 1, Medan. 9 (1) : 4853

Yulianti SR, Mukaddas A, Faustine I 2012. Profil pengobatan pasien diabetes melitus di instalasi rawat inap RSUD undata palu. 3(43). 